\title{
SILDISTUSE RETOORIKA
}

\author{
LINNAR PRIIMÄGI
}

$\mathrm{R}$ etooriliste võtete hulka kuulub sildistus ehk isikunime kui konventsionaalse märgi asendus esmalt indeksmärgisega: tüübinimi, karakterinimi, anekdoodinimi, ja viimaks sümbolmärgilisega: müüdinimi. Teadlik sildistus viiakse läbi järk-järgult, astmeliselt. Sildistada ei saa ühtviisi tulemuslikult mitte igat inimest. Kõige väljakutsuvam selleks on markantne isiksus.

Isiksus esineb oma pärisnime all. Pärisnimi on meie mittearhailises ühiskonnas inimest tähistav konventsionaalne, kokkuleppeline märk. Vanemad lepivad kokku, mis nime nad lapsele panevad. Ristides saab laps valikuliselt veel lisanime kaitsepühakult. Perekonnaringis võib last kutsuda ka hoopis registreerimata nimega: luuletaja Rainer Maria Rilke ema kutsus poega Sophiaks.

Meie kultuurkonnas on pärisnimi tinglik ja neutraalne indeksmärk, mis osutab konkreetsele inimesele, mitte millelegi muule, ehkki mõni nimi toob „mürana” paratamatult kaasa mitteneutraalseid kõrvaltähendusi: „Eestis on lastele antud teisigi kurjakuulutavaid nimesid: Lucifer, Daemon, Banda, Angry..." (Sang 2011: 929).

Inimene võib oma nimetähist vahetada, st muuta kokkulepet, kuidas teda edaspidi peab kutsutama. Abiellujad otsustavad, kumma osapoole perekonnanimi valida - või siis hoopis võtta liitperekonnanimi. Kati Vasar võttis abielludes nimeks - ja sai tuntuks kui kirjanik - Kati Murutar, uuesti abielludes sai temast Kati Murdmaa ja viimaks Kati Vatmann. Ja kõige lõpuks: „„Nimi, mis mu järgmise raamatu kaanele tuleb, on Kati Vasar-Murutar-Murdmaa," seletab Kati...” (Kati perekonnanimeks... 2011).

Pärisnime tinglikkust näitab akronüümistuse võimalus. Akronüüm on stilistiliselt neutraalne nimekuju, mille ainus ülesanne on äratuntavus. Enamatähelised akronüümid, NATO, CCCP, on hõlpsamalt identifitseeritavad kui vähematähelised. Režissöör Oliver Stone’i filmi pealkiri „JFK” (1991) viitab küllalt selgesti USA presidendile John F. Kennedyle. Ent üksnes asjassepühendatud mõistavad, et lauses „B. kiitles liberalismiga ning oli südamepõhjas puhtakujuline aristokraat" peab prantsuse kirjanik Prosper Mérimée silmas oma kolleegi Stendhali - kodanikunimega Beyle (d'Ormesson 1997: 175).

Loomeinimest võib samuti identifitseerida neutraalne varjunimi - autorinimi, pr nom de plume kirjaniku kohta. Henri Beyle sai kuulsaks kui Stendhal - nime all, mille ta võttis imetletud antiikkunstiteadlase Johann Joachim Winckelmanni sünnilinnalt Saksamaal. Aleksei Peškovi tuntakse Maksim Gorkina ning Anton Hansenit Tammsaarena.

Prantsuse keele grammatika käsitab pärisnimena ka isiku rahvuskuuluvusele osutavaid nimisõnu: need kirjutataksegi suure algustähega (Dubois jt 1986: 186). Eesti keeles on etnonüüm neutraalne nii kunstnikunimena, El Greco, st Kreeklane, kui ka cognomen'ina: Theophanos Kreeklane, Läti 
Henrik, samal ajal kui rahvuse nimi ise võib olla pejoratiivne: „Lätlane... Lette; - (scherzh.) ein Häufchen Menschenkoth" 'inimsitahunnik(uke)' (Wiedemann 1973: s.v).

Sildistus seisneb pärisnime asenduses hüüdnimega. Hüüdnimi kinnistub analoogia põhjal - seda kindlamini, mida tugevam on analoogia. Ilma veenva analoogiata on pelk sõimunimi: „...Telenuustikuna tuntuks saanud Enn Eesmaa... ühesilmne naiskapten [Kadri] Simson... Marika Tuus-Laul, töönimega Nüri Knopka... Mailis Reps, töönimega Ennäe Kes Ükskord Haridusministriks Sai!" (Raid 2013: 126-128).

Sildistatava ja hüüdnime-sildi analoogia saab olla kas okasionaalne: juhuslik, väline või kontseptuaalne: olemuslik, imagoloogiline.

Puhtvälise analoogia põhjal omistatud hüüdnimi võidab ilmsuse määral: „Eesti president oli tollal Lennart Meri, keda kutsuti Kaameliks. Hüüdnimi tuli käibele pärast seda, kui luuletaja Debora Vaarandi märkas presidendi sarnasust Eduard Viiralti graafilisel lehel kujutatud loomaga. Kaameli pilk on tark ja elukogenud, kaelahoiak uhke ja enesekindel" (Vahter 2012).

Ent väline analoogia, mis tugineb üksnes look'ile või tegevusele, on okasionaalne, juhuslik, sest välimus ja tegevusala võivad ajapikku muutuda ning hüüdnimi ununeda - koguni ühes sellega, kes seda kunagi kandis. Kes mäletab Suure Prantsuse Revolutsiooni aegset funktsionääri Joseph Fouchéd hüüdnime järgi, millel pole isegi korralikku eestikeelset vastet: mitrailleur de Lyon - Lyoni Kartetšist; sks der Schlächter von Lyon ('Lyoni Lihunik') - kes tuvastab veel Lyoni Lihuniku nime järgi natsikurjategija Klaus Barbie? Kes mäletab, et „läkski peaminister [Juhan Parts] pimeduse katte all kraanaga ja relvastatud „korrakaitsjatega” Lihulasse, et vägivaldselt Eesti vabadusvõitlejate mälestuseks püstitatud ausammas eemaldada. See maksis talle küll peaministri ameti ja isegi ta parteikaaslased hakkasid teda Lihula lihunikuks kutsuma..." (Toomepuu 2013).

Välimuse või tegevuse okasionaalsel alusel omistatud hüüdnimi võib olla kas tüübinimi või karakterinimi.

Tüübinimi on tegelikult suuretäheline üldnimi: Kaamel, Mõjuagent, Ondatra: vuntsidega Siim Kallas (Vahter 2012). Suurt algustähte võivad asendada ka täiendid: „tüüpiline reformierakondlane”, „sotsiaaldarvinisti musternäide”, „poliitik par excellence”, „lihtsalt üks võrgutaja”, „üks kuradima kommunist”, „aristokraat mis aristokraat”.

„Nagu Kerenski hiljem oma memuaarides kirjutas, oli üks viimaseid Petrogradi vaateid, mis tema silme ette kerkis, [kui ta Ajutise Valitsuse peaministrina 25. oktoobril 1917 linnast lahkus,] tohutute ebaühtlaste tähtedega kiri seinal: „Maha juut Kerenski, elagu Trotski!”” (Vert 2003: 110). Aleksandr Kerenski oli tõesti juudi verd. Kurioosseks muudab sildistuse Juut aga asjaolu, et ka Lev Trotski oli juut - kodanikunimega Bronštein.

„Vene propagandatalitused on välja mõelnud sõna „russofoob”, millega püütakse sildistada iga inimest, kes väljendub Venemaa suhtes kriitiliselt. Eesmärk on välistada igasugune Vene juhtkonna arvustamine" (Tänavsuu 2011).

„Kui võrrelda Käbiniga, oli Lennart Meri alguses ikka kehkadivei, naljategu” (Kressa 2015).

„President Toomas Hendrik Ilves rääkis varsti pärast ametisse astumist USA saadikule, et Keskerakonna esimees Edgar Savisaar on ebausaldusväär- 
ne populist, selgub Postimehe andmeil Wikileaks'i andmebaasina tuntuks saanud USA saatkonna salajastest memodest” (Wikileaks... 2011).

Tüübinimi on sildina enamasti negatiivne (Laineste 2008).

Karakterinimi on individuaalsem ja motiveeritum kui tüübinimi. Tüübinimi üldistab, karakterinimi konkretiseerib: naissoost geograafiaõpetaja sai hüüdnimeks Napoléon „rämeda hääle, sõjaka ilme, meheliku kõnnaku pärast” (Ušakov jt 1981: 120).

Karakterinimeks võib nime muuta spetsiifiline täiend.

„Nikolai Romanov I - Nikolai Kaikamees - ja Nikolai II - Verine - näitasid vene rahvale maksimaalselt võimalikku ja võimatut... timukaliku meetodi alal" (Lenin 1955: 28).

„,'Mida kuritegelikku oli Ida-Saksamaal?” küsis omal ajal Ida-Saksamaal Punaseks Nõiaks kutsutud Margot Honecker...” (Honeckeri lesk... 2012).

„Kommuuni kangelannaks oli õpetaja Louise Michel... „Montmartre’i Punane Neitsi”, nagu teda rahva hulgas kutsuti” (Averjanov jt 1973: 20).

Karakterinimi võib ka tervikuna olla võetud kultuuriloost: moolok, casanova, kvisling, oblomov. Kirjaviisilt on need eesti keeles kodunenud erineval määral, aga igaüht iseloomustab mitmusliku vormi võimalus: „igasugused moolokid, casanovad, kvislingid, oblomovid". Kultuurilooline karakterinimi on spetsiifiline, konkreetne - ainuliselt äratuntav: mooloki taga on muistne ammonlaste jumalus Moolok, kvislingi taga ajalooline Vidkun Quisling, oblomovi taga Ivan Gontšarovi romaani nimitegelane Ilja Iljitš Oblomov.

Pelgalt välisele, sarnasuse ja tegevusala analoogiale tuginev kultuurilooline karakterinimi jääb vaid põgusaks, seejuures alati kaheldava õigustusega hüüdnimeks: kui liiga lai. Nii sildistas Gustav Suits: „[Jaan] Tõnisson on meie Napoleon, [Johann Voldemar] Jannsen meie Shakespeare, Ernst + Otto Peterson meie Molière, [August] Weizenberg meie Thorvaldsen" (Suits 1913: 44).

Kui saksa kirjanik Emil Ludwig 13. XII 1931 küsis Jossif Vissarionovitš Stalinilt: „...kas Te peate võimalikuks paralleeli enda ja Peeter Suure vahel? Kas te peate ennast Peeter Suure töö jätkajaks?”, siis vastas Stalin: „Mitte mingil viisil. Ajaloolised paralleelid on alati riskantsed. Kõnesolev paralleel on mõttetu. [---] Peeter tegi väga palju mõisnike ja kaupmeeste rahvusriigi loomiseks ja tugevdamiseks. [---] Ülesanne, millele ma pühendan oma elu, seisab teise klassi ja nimelt töölisklassi ühendamises. Selleks ülesandeks ei ole mingi „rahvusliku” riigi tugevdamine, vaid sotsialistliku ja järelikult internatsionaalse riigi tugevdamine..." (Stalin 1952: 100-101).

Sama kistud on nüüdisaegsed ümberristimiskatsed: „,Agressioon on sama ja selle juht sarnaneb väga Peeter Suurega. Pole saladus, et Peeter Suur on üks [Vene Föderatsiooni presidendi Vladimir] Putini ikoone. Putin tahab teda jäljendada," sõnab [Ukraina riikliku filmiagentuuri juht Filipp] Iljenko" (Kuusk 2015).

Karakterinimi on individualiseeritum kui tüübinimi. Siin kehtib mõiste mahu ja sisu pöördvõrdelisuse seadus, mida tunneme loogikast: tüübinimi hõlmab rohkemaid eksemplare, aga pealiskaudsemana edastab oluliselt vähem iseloomulikku teavet: Võrgutaja on mõistena laiem kui casanova, aga casanova on sisukam kui „lihtsalt võrgutaja”. Neitsi hüüdnime on kandnud mitmed, kuid neid eristab personaalne täiend: Orléans'i neitsi - Jeanne d'Arc, Montmartre’i Punane Neitsi - Louise Michel, Vallimäe neitsi - Jaak Järve romaani tegelane (1885). 
Iga karakterinimi viitab mingile kultuuriloolisse pärimusse kuuluvale või siis võimalikulegi faabulale: loole (Priimägi 2011). Karakterinimed shylock, harpagon, gobseck, Ihnus Rüütel ja pljuškin täpsustavad kõik üht ja sama üldnime Ihnuskoi, ent igaüks implitseerib omaenda looga seostuva tausta. Samamoodi tulevad igaüks viitega oma faabulale Punane Parun, Punane Nõid, Punane Hanrahan ja Morten Punane.

Faabulat implitseerivat karakterinime võib kutsuda anekdoodinimeks. Anekdoodinimi kui isikunimeline collectivum võib esineda nii ainsuses kui ka mitmuses: „igat sorti shylockid”, „tänapäeva pljuškinid”. Anekdoodi keskne tegelane ei olegi muud kui faabula karakter, mitte ajalooline tegelane, kelle isikunimi talle on omistatud: Puškin, Tšapajev, Brežnev.

„M[ihhail] Bulgakovil „Meistris ja Margaritas” „Nikanor Ivanovitš... ei tundnud üldse luuletaja [Aleksandr] Puškini teoseid, kuid teda ennast tundis väga hästi ja kasutas iga päev mitmeid kordi lauseid, nagu: „Ja korteri eest maksab Puškin või?"'... Puškin on kõikide nende absoluutne universaalne substituut, kes ei täida oma funktsiooni kas üldse või siis mitte nii, nagu peab" (Volgin, Narinski 1993: 133).

Seda kinnitab tõsiasi, et karakterile antud konkreetne isikunimi on väljavahetatav. Anekdooti poliitikust, kes napi keeleoskuse tõttu ei tervitanud Inglise kuningannat mitte lausega „How are you?”, vaid „Who are you?”, räägitakse nii Vene Föderatsiooni presidendi Boriss Jeltsini kui ka Eesti Vabariigi presidendi Arnold Rüütli kohta. Anekdoodinimega sildistatud inimest peab olema võimalik kujutleda episoodi, kus tegutseb talle hüüdnime andnud karakter.

Paariti või hulgi külgepandud karakterinimed hõlbustavad faabula reproduktsiooni: Andres ja Pearu, Romeo ja Julia, Must ja Valge Koer, Kolm Musketäri... Edgar Savisaar: „Selle peale tuli mulle meelde omaaegne „seitsme päkapiku koalitsioon” Tallinnas kümmekond aastat tagasi. Mitte ühtegi küsimust ei suudetud lahendada, linnaelanikud olid päris õnnetud, et neile olid sattunud niisugused valitsejad. Kaklesid omavahel, nii et karvatutid lendasid" (Kümme kevadsuvist... 2013).

Välisele analoogiale tuginev karakterinimi teiseneb anekdoodinimeks sõltuvalt selle nime levila kultuuritasemest. Küündimatu haridusega avalikkus ei tarvitse teada, kes olid Moolok, Stepan Pljuškin, Punane Prints või Punane Parun. Lisaks võib ühel nimel olla mitu analoogset tähendust, mis võivad aja jooksul tundmatuseni muutuda. Nimi Nimrod, mis algul märkis niihästi osavat jahimeest kui ka Jumala-vastases ülbuses Paabeli torni ehitada lasknut, omandas millalgi tähenduse Türann ning on tänapäevases angloameerika uususes kasutusel kui Põmmpea (McNamee 2010: 16./17. IV 2011).

Hüüdnimesid antakse ka stiihiliselt. Silmatorkavad isiksused pälvivad neid rohkem kui ühe.

,...Pariisi ajakirjandus läks äärmiselt enesekindluselt üle täielikule meeleolu langusele ja varjamatule hirmule. Tüüpiliseks tema käitumisele neil päevil oli epiteetide range järjestikkus, mis lisati Napoléoni nime juurde sedamööda, kuidas arenes tema pealetung lõunast põhja poole. Esimene teade: „Korsika koletis maabus Jouani lahes.” Teine teade: „Inimsööja läheneb Grasse’i linnale.” Kolmas teade: „Usurpaator asus Grenoble'isse.” Neljas teade: „Bonaparte hõivas Lyoni”. Viies teade: „Napoleon läheneb Fontainebleau'le”. Kuues teade: „Tema Keiserlikku Majesteeti oodatakse täna talle ustavasse Pariisi”. Kogu 
see literatuurne gamma mahtus mõne päeva jooksul ühe ja sama toimetuse juures ära ühtede ja samade ajalehtede veergudele" (Tarle 1964: 386).

Dominantsetele ja vastuolulistele isiksustele massilises tüübi- ja karakterinimede omistuses võib saabuda küllastuse seisund, kus avalikkus kaotab imagoloogilise ja maineorientatsiooni. „[Veebilehe] Telegrami aastaküsitlusele vastajad valisid [Eesti Keskerakonna esimehe Edgar Savisaare] nii kõige vähem usaldusväärsete kui ka kõige usaldusväärsemate poliitikute toppi” (Telegrami... 2015).

Üht ja sama inimest sildistatakse läbisegi vastandlike hüüdnimedega, nii et enam pole võimalik otsustada, kes ta õigupoolest on - kõik sildid on ühtviisi õiged ja valed. Prantsuse ajaloolane Patrick Ravignant nendib seda määratluste tulva Napoléon Bonaparte’i puhul: „Väga raske on säilitada ranget erapooletust isiku suhtes: Napoléon kutsub meis esile liiga erinevaid reaktsioone, samastub liialt oma mustade ja kuldsete müütidega, äratab ülemäära kirgi, positiivseid või negatiivseid. Tema karjäär on nii tihe, see hõlmab nii paljusid vastuolusid, et siin leiavad hõlpsasti kõlapinda kõige vastandlikumad väited. Vallutaja, kes ei armasta sõda, rahutooja, kes rahu käes igavleb, lepitaja, kes surub maha opositsiooni, despoot, kes õhutab vastuhakku, modernistlik ning isegi futuristlik vaim, keda jälitavad mineviku triumfid, lakkamatu unistaja, kes vaimustub meetodist ja loogikast, pragmaatiline realist, kes hõõgub romantilises palavikus - see on vastandlike tendentside vihk" (Petiteau 2004: 11).

Sama vastuoluline on Napoléoni-pilt XIX sajandi venelaste kollektiivses mälus, mida peegeldab tollane ilukirjandus: Fjodor Dostojevski, riivamisi ka Lev Tolstoi looming, kus Napoléon on „teema” ja „legend” ning „anekdoot”, „müüt”, „sümbol”, „idee”, „eeskuju” ja „kultus” - nii et pärisnimest muutus Napoléon üldnimeks. Ta on korraga „sajandi inimene”, „kurjategija”, „usurpaator”, „antikristus”, „märter”, „tavatu ja kummaline nähtus”, „tohutult kõrk”, „piiritu inimpõlgur”, „naiselik intriigimeister”, „tühine ennasttäis poosetaja”, „kõige geniaalsem väejuht”, „tõusik”, „parvenüü”, „keisriks pürginud endine suurtükiväekapten”, „provintsi- ja kasarmuhing”, „meeleheitlik avantürist”, „naiivne ja lihtne”, „kannataja”, „üleinimliku võimu ori”, „autoriteet”, „lääne kultuuri fenomen”, „kolmanda seisuse eestvõitleja Prantsusmaal ja väljaspool Prantsusmaad”, „suur ja kaasaegne”, „Mephistopheles”, „kiusaja vaim”, „kõikide Jumala ning inimseaduste rikkuja, kes kehastab õigust verd valada, käsutada inimelusid”, „võimutahte kehastus”, „süümest ja moraalist lahtiütleja”, „saatanlik”, „mõõdutult kõrk”, „valitsushimuline”, „despoot” (Volgin 1993).

„Kui Edgar Savisaarel õnnestub [hüüdnimetsi ja karikatuurides] ühekorraga olla nii „Juan Perón” kui ka „Leonid Brežnev”, nii „Adolf Hitler” kui ka „Winston Churchill”, nii „Louis XVI” kui ka „Vladimir Meciar”, nii „Helmut Kohl” kui ka „Paavo Väyrynen”, nii „Kalevipoeg” kui ka „Feliks Dzeržinski”, nii „minevikuihaleja” kui ka „moodsamale maailmale orienteeruja”, nii „Trooja hobune” kui ka „ninasarvik”, nii „galantne kavaler” kui ka „macho”, nii „naistesõber” kui ka „naistepõlgur”, nii „noorteiidol” kui ka „lasteahistaja”, nii „luuser” kui ka „miljonär”, nii „gangster” kui ka „Eesti poliitika ristiisa”, nii „paksuke” kui ka „kiiruseületaja”, nii „rockikuningas” kui ka „puuslik”, nii „Savipäts” kui ka „võipakk”, nii „Keskerakonna jõufiguur” kui ka „oravapartei maskott”, nii „turuliider” kui ka „lootusetu kaotaja”, nii „poksija” kui ka „sumomaadleja”, nii „suur taktik” kui ka „lindistaja”, nii „Eesti NSV kukutaja” kui ka „,idameelne”, nii „hullem punaparunist” kui ka „rahvamees”, nii „Savi” kui ka „Raudne 
Kesk" [jutumärgid lisatud - L. P.] - kui ühel inimesel õnnestub seda kõike olla ühekorraga, siis ulatub ta ilmselt üle igast omistatud rollist" (Priimägi 1999b).

Sven Mikser: „Kujundatud müüt temast tähendab, et ta tekitab inimestes oma lähedalviibimisega väga suurt aukartust. Ükskõik kuidas siis temasse suhtutakse, kas hästi või halvasti. Kujundatud müüt annab talle väga vabad käed. Kui teiste poliitikute valijad armastavad poliitikute programmi, maailmavaadet või lubadusi, siis Edgar Savisaare valijatest väga suur osa armastab personaalselt Edgar Savisaart. [---] Paljud tema teod võiks hävitada - ja jäädavalt - ükskõik kelle teise maine, aga Edgar Savisaar läheb justkui järjest immuunsemaks" (Tammer 2005).

Olukorras, kus puudub võimalus omal käel veenduda ühe või teise omistuse õigsuses, leiab kollektiivses teadvuses aset mingi „vastandite kokkujooks” ja minnakse üle sümboliseerivale režiimile. Tegelik inimene ei huvita sel juhul enam kedagi, vaid on „teadagi kes”. Too „teadagi kes” tähendab, et mitte keegi täpselt ei tea. Sealt avaneb mütologiseeringu võimalus (Priimägi 1999b).

Isiku pärisnimi omandab ise „katus-sildi” funktsiooni, muutub sümboliks - müüdinimeks. Usundiloolase Mircea Eliade järgi tähistab seda mütoloogiline coincidentia oppositorum: „vaheldumisi või koguni samaaegne lahkus ja kohutavus, loovus ja hävitavus, solaarsus ja reptiilsus - actus ja potentia" (Eliade 1958: 419).

Napoléonist saab „Napoléon”, Edgar Savisaarest „Edgar Savisaar” - isiksusest saab müütiline tegelane. Müütiline isik muutub sotsiaalseks orientiiriks, mida ennast kardetakse samavõrd kui tema kaotust.

„Ometi on terava mõistuse ja uskumatu kombineerimisandega [Edgar] Savisaare müüti läinud vaja nii roosas kampsunis memmel Keskerakonna kongressil kui ka reporteril ajalehe toimetuses. Kõige rohkem on seda müüti läinud vaja aga Savisaare vastastel. Suurem osa Eesti poliitilistest otsustest on tehtud, Edgar Savisaare nimi huulil. Jah, ütlevad nad, see otsus on kehv, aga Savisaar oleks veel kehvem. Kust leiab Eesti poliitika uue vaenlase?" (Raud 2004).

Siis jõuab sildistusprotsess lõpule: inimese enda nimi naaseb, ent juba individuaalse ja konstantsena. Siis on pärisnimi - eesnimi ja/või perekonnanimi ise muutunud kategooriaks, pantserdunud jutumärkidesse.

„Kunagi ütlesin Tuuli Kochile lause, mille ta avaldas oma Savisaare-raamatus: „Kas te kujutate ette reformierakondlast, kes paneb oma lapsele nimeks Edgar?" - Mitte ükski reformar ei taha oma last niimoodi sildistada" (Priimägi 2015).

Erinevalt karakterinimest ei saa müüdinime kasutada mitmuses - tegu on unikaalse isikliku sildiga. Ainuline nimekuju tagab individuaalse üleajalise identifitseeritavuse. Ei ole olemas mitut „Edgar Savisaart”. Nimi „Edgar” tähendab praeguste eestimaalaste kollektiivses teadvuses kontekstivabalt ainult Edgar Savisaart.

„Ajakirja X 2000. aasta jaanuarinumbri küsimusele „Kelle sa tapaksid, kui oleks võimalus?" vastas Stockholmi Eurovisiooni lauluvõistlusele Eestit esindama saadetav noor levilaulja Eda-Ines Etti: „Edgari”” (Priimägi 2000).

„Kui [Reformierakonda astunud] Vilja Savisaar ei loobunud lahutatud abikaasa nimest, ei imestanud enam keegi, sest Savisaare nimi töötab - ole sa kus parteis tahad" (Vainküla 2015).

Omaenese nimega sildistatud inimene muutub müütiliseks tegelaseks. Ajakirjanik Kalle Muuli õigustas Eda-Ines Etti ütlust sellega, et „Edgar Savi- 
saar olevat „pesueht müüt. Ta on kuri geenius, pimedusest sirutuv karvane käsi, rahva painav ajaloomälu, meie sisepoliitiline Venemaa ja kõikvõimas KGB ühes isikus”, mistõttu „ei maksa Savisaarel ka pahandada Eda-Ines Ettiga, kes ajakirjas X avaldas soovi tappa Edgar. Nooruke eurolaulja ei saanud kindlasti silmas pidada päris-Edgarit, keda ta ei tunne, vaid ikka üksnes müüdiEdgarit, kelle tapmine pole patt, vaid kangelastegu"” (Priimägi 2000).

Müüdinime erinevus anekdoodinimest on põhimõtteline (Priimägi 1999a). Anekdoot edastab vähetuntud tõsielulisi seiku, mida võib kaunistada väike väljamõeldis - müüt seevastu ei dokumenteeri muud kui iseennast ja võib vabalt olla tervikuna „vale”. Nii pidas lugeja enesestmõistetavaks hakata lugu säädu seadma, kui oli segi aetud Henry Fordi ja Gerald Fordi nimi (Grabbi 1999). Müüdi kallal pole niisugune „vigade parandus” mõeldav. Anekdoodi võib seega rohkem või vähem õigesti, rohkem või vähem täielikult üles kirjutada - anekdoot ongi lugu ise -, müüdist aga saab jäädvustada vaid mittekohustusliku interpretatsiooni, sest müüt on midagi kõikide teda peegeldavate lugude tagust.

Anekdoodi tegelane võib näida imelik - müüdi kangelane on salapärane. Müüdi kangelase salapära põhineb sümboli põhimõttelisel lõpuniseletamatusel ning osutub tänu sellele sügavalt kunstiliseks, erinedes anekdoodi tegelase pelgast mõistatuslikkusest. Sellele erinevusele osutab Juri Lotman, rääkides „quasi-kunstilistest teostest, mis tegelikult esitavad üksnes äraarvamisülesandeid. Säärased on rahvaluules mõistatused, uusima aja kunstis aga tohutu detektiivvaldkond. Detektiiv kujutab endast ülesannet, mis teeskleb kunsti" (Lotman 1992: 187). Ka detektiivlood liigituvad olemuselt anekdootide, mitte müütide hulka.

Anekdoodi tegelase ümber luuakse koduselt humoristlik õhustik, samal ajal kui müüt võib sisendada hirmu. Anekdoot kahandab isiklikku distantsi peategelasega, võtab maha aukartuse tema ees ja juhib lõpuks familiaarsusse, kohatusse omamehelikkussegi. Just distantsipuudust võib täheldada suhtumises „meie Lennartisse”, nagu see ehmatava selgusega ilmnes tema Viimsi maja ehitusega seoses. Ain Kaalep pidas isegi vajalikuks rahvast korrale, suuremale respektile kutsuda: „Jätke mõnitamine!” (Kaalep 1999).

Anekdoot kujuneb teatrilaval sketšiks, müüdi kangelase saatus võtab paratamatult traagilise värvingu. Nii sai Lennart Mere jäljendamisest näitleja Egon Nuteri leivanumber. Igal juhul ei ole sketši või paroodia puhul tegemist pahatahtliku irvitamisega, mida pühendamata publikus võib näiteks esile kutsuda müüdikangelase traagiline saatus. Urmo Soonvald kirjutas NO99 lavastuse „Savisaar” kohta, et „Vana-Kreeka mütoloogilise jutustusena edasi antud [Edgar] Savisaare moraalne tammumine kohapeal oli täis teravusi" (Soonvald 2015).

Anekdoot on mineviku seigake, millest tuleviku tarvis võib üht-teist tähele panna. Koolilõpetajatele 1999 jutustas president Lennart Meri oma vastuvõtul sellest, kuidas 1953. aastal lõpetas kõrgkooli tema ja mille poolest tuna erineb tänast. Müüt aga puudutab tulevikku püsivamalt ja vahetumalt kui anekdoot. Sest anekdoot võib kollektiivsest mälust kustuda, meelest minna, müüt aga ise ongi kollektiivse mälu generaator.

Anekdoodi tuumaks on pointe, argieluga toimetuleku ootamatu viis, siinpoolse probleemi ratsukäiguline lahendus. Müüdi tuuma seevastu moodustab 
sümbol, mis ulatub siinpoolsusest üle või välja. Anekdoot lõpeb punktiga (pr pointe 'punkt'), müüt on lakkamatult iseennast regenereeriv struktuur.

Müüdinime kandva isiksusega võrreldakse teisi, teda ennast enam kellegagi ei võrrelda. Võrdlust Adolf Hitleriga on filosoof Leo Strauss aastal 1951 käsitanud koguni omaette sildistava propagandavõttena reductio ad Hitlerum.

„Internetikommentaariumide kohta on Mike Godwin sõnastanud seaduse, et suvalise vaidluse edenedes kasvab natsisüüdistuste kasutuselevõtu tõenäosus. Kodanik Rein Raud võttis selle silmapaistva sildistamisargumendi kasutusele juba minu Diplomaatias avaldatud ettekande „Infokonfliktid ja enesekaitse" esmasel käsitlemisel..., luues selle reductio ad Hitlerum lähenemisega temale omase „salliva” [jutumärgid lisatud - L. P.] õhustiku akadeemilise arutelu jätkamiseks" (Aaviksoo 2011).

Hitleriga on võrreldud mitmeid poliitikuid: mh Mihheil Saakašvilit ja Vladimir Putinit. „[Vene Föderatsiooni presidendi Vladimir] Putini võrdlemist Hitleriga on kombekas välispoliitikas seni peetud pigem hüsteeriliseks liialduseks. Ometi on pärast Krimmi annekteerimist ja eriti Putini 18. märtsi kõnet selle paralleeli välja toonud Rootsi välisminister Carl Bildt, Kanada peaminister Steven Harper, senaator John McCain, Hillary Clinton, Zbigniew Brzezinski, rääkimata erinevatest analüütikutest ja kolumnistidest" (EerikNiiles Kross võrdleb... 2014).

„...ilmus Briti troonipärija prints Charles „vabandus” venelaste ees, kui ta võrdles president Putinit Hitleriga" (Prints Charles... 2014).

Adolf Hitlerit ei ole tavaks kellegagi võrrelda.

Nõnda võib müüdinimi omakorda muutuda karakterinimeks ja minna ise käibele uues, kellegi teise sildistustsüklis.

Sel juhul võib pärisnimi ka kollektiviseeruda erakondlikus tähenduses: šovinistid, marksistid, hitlerlased, savisaarlased. Stendhali puhul: „Tänapäeva raevukad beylistid, niisama tulised oma ebajumalduses nagu kaasaegsed oma ükskõiksuses - „beylandid”, ütles [kirjanik Valery] Larbaud pisukese julmusega" (d'Ormesson 1997: 173).

Kuid ka siin eristuvad efemeersed ad hoc-moodustised kultuurilooliselt rohkem kinnistunutest, tabavamatest, imagoloogiliselt põhjendatumatest. Banderalased ei seostu mitte ainult Stepan Bandera nimega, vaid ka odioosse sõnaga „bande”. Aga kui palju on fontellenism, mille Stendhal omistas oma emapoolsele vanaisale (Maurois 1980: 465), veel seotud Bernard Le Bovier de Fontenelle'i endaga?

Vastase teadlik sildistus on propaganda(sõja) ala - avalik ja suhteliselt lihtis, kui teada ja vallata võtteid. Hoopis keerulisem on seesama protsess imagoloogias, kus see ei tugine mitte välisele, vaid seesmisele analoogiale, mille tugevus sõltub dominantsete loomujoonte kaalust ning arvust. Hüüdnime, mis põhineb seesmisel, kontseptuaalsel analoogial, võib kutsuda kuvandinimeks.

Kuvandinimi võib olla niihästi eksplitsiitne kui ka implitsiitne. Lennart Mere kuvandit ei kajastaks implitsiitselt mitte Kaamel, vaid hoopis Delfiin: terane, läbimõeldud, kaval, sügav, meeldiv, rõõmus, unikaalne. Tabav hüüdnimi aktualiseerib sildistatava imagoloogilise skaalaprofiili. Omadused suur, raske, pealetungiv, loomne, aeglane, vali, kare, kauge, rammus, ühetaoline on - nagu näitab kuvandianalüüs - dominantsed nii Edgar Savisaare kui ka 'ninasarviku' kuvandis. Samad 'ninasarviku' kuvandijooned - suur, raske, pealetungiv, 
loomne, aeglane, vali, kare, kauge, rammus, ühetaoline - domineerivad kontseptis 'Venemaa', millega Edgar Savisaart samuti tulemuslikult seostatakse. Ent Ninasarvikust ei ole saanud Edgar Savisaare eksplitsiitset nimesilti.

Olgu see lisatud eristamaks propagandistlikku sildistust ning imagoloogilist kuvandust, millesse me siin ei süvene.

\section{Kirjandus}

A a viks o o, Jaak 2011. Valed ja pooltõed on olemas ja elus. - Eesti Päevaleht 30. III.

A v e r j a n ov, Aleksandr P., G a l k in, Ilja S., Z u b o k, L. I. jt 1973. Uusaeg. II osa. Õpik keskkooli IX klassile. 9. trükk. Tallinn: Kirjastus Valgus.

d'O r m e s s o n, Jean 1997. Une autre histoire de la littérature française. Paris: NiL éditions.

Dubo is jt 1986 = Жак Дюбуа, Франсис Эделин, Жан-Мари Клинкенберг, Фидипп Мэнге, Франсуа Пир, Адлен Тринон, Общая риторика. Москва: Прогресс.

Eerik-Niiles Kross võrdleb Putini kõnet ja Hitleri kõnesid. - Postimees 21. III 2014. E li a d e, Mircea 1958. Patterns in Comparative Religion. New York: Sheed \& Ward.

G r a b b i, Rein 1999. Gerald Ford elab! - Postimees 20. V.

Honeckeri lesk viskus DDR-i kaitsele. - Eesti Päevaleht 5. IV 2012.

K a a l e p, Ain 1999. Jätke mõnitamine! - Sõnumileht 14. V.

Kati perekonnanimeks saab Vasar-Murutar-Murdmaa. - elu24.postimees.ee 11. II 2011.

Kr e s s a, Kaarel 2015. ENSV kunagise peremehe abi: Johannes Käbini puhul oli haruldane, et ta polnud mölakas. - Eesti Päevaleht 6. IV.

$\mathrm{K}$ u u s k, Hendrik 2015. Ukraina riikliku filmiagentuuri juht: Putin on nagu Peeter Suur. - Eesti Päevaleht 20. II.

Kümme kevadsuvist küsimust Edgar Savisaarele. - Kesknädal 5. VI 2013.

L a in este, Liisi 2008. Vaenunimedest eesti internetis. - Mäetagused, nr 38. http://dx.doi.org/10.7592/MT2008.38.laineste

L e n i n, Vladimir Iljitš 1955. Aprilliteesid. Tallinn: Eesti Riiklik Kirjastus.

L o t m a n 1992 = Юрий Михайлович Лотман, Культура и взрыв. Москва: Гнозис, Издательская группа Прогресс.

M a u r o i s, André 1980. Stendhali „Punane ja must”. - Stendhal, Punane ja must. XIX sajandi kroonika. Tallinn: Eesti Raamat, lk 463-477.

M c N a m e e, Gregory (koost) 2010. The Word Origin 2011 Calendar. Denver, Colorado: Accord Publishing.

P e t i t e a u, Natalie 2004. Napoléon, de la mythologie à l'histoire. Paris: Éditions du Seuil.

Pr i i m ä g i, Linnar 1999a. Anekdoot ja müüt. - Eesti Ekspress 2. XII.

Pri i mä gi, Linnar (koost) 1999b. Savisaare mütoloogia \& mütoloogiline Savisaar. Tallinn: Keskerakond.

P r i i m ä g i, Linnar 2000. Ühe imago analüüs. - Eesti Ekspress 24. VIII.

P r i i m ä g i, Linnar 2011. Motiiv - narratiiv - sümbol - tekst. Teesid motiivianalüüsist. - Keel ja Kirjandus, nr 7, lk 526-535. 
P r i i m ä g i, Linnar 2015. „Savisaar” ja Savisaar. - Pealinn 25. II.

Prints Charles „vabandas” venelaste ees, et võrdles Putinit Hitleriga. - Delfi 23. V 2014.

R a i d, Juku-Kalle 2013. Eelarve. Friigikogu rahvuseepos. Tallinn: Ema ja Isa. R a u d, Mihkel 2004. Puhka rahus, Edgar Savisaar! - Eesti Päevaleht 12. X. S a n g, Joel 2011. Nomen est nomen. - Keel ja Kirjandus, nr 12, lk 929-931. S o o n v a ld, Urmo 2015. „Savisaare” muusikalist: monument Eesti-pimedale poliitikule, keda äratab vaid Lasnamägi. - Eesti Päevaleht 7. II.

St a li n, Jossif V. 1952. Teosed. 13. köide: juuli 1930 - jaanuar 1934. Tallinn: Eesti Riiklik Kirjastus.

S u i t s, Gustav 1913. „Noor-Eesti” lähematest ülesannetest käesoleval ajal. - Eesti Kirjanikkude Seltsi „Noor-Eesti” Aastaraamat I. Tartu: E.K.S. „Noor-Eesti” kirjastus, lk 40-47.

T a m m e r, Enno 2005. Mikser tõlgib arusaadavamaks Savisaare võimumängud. - Postimees 12. XI.

T a r l e, Jevgeni V. 1964. Napoleon. Tallinn: Eesti Riiklik Kirjastus.

Telegrami lugejate jaoks usaldusväärsed poliitikud keelduvad intervjuudest. - Telegram 24. II 2015.

T o o m e p u u, Jüri 2013. Eesti - Putini Trooja hobune NATOs ja Schengeni tsoonis? - Delfi 6. VII.

T ä n a v s u u, Toivo 2011. Ants Laaneots, mina küll ei käi Moskvas „Ameerikat avastamas". - Eesti Ekspress 27. II.

U š a k o v jt 1981 = Н. Н. Ушаков, В. Д. Васильева, Н. П. Клюева, О грамматических особенностях прозвищных имен. - Л. П. Калакуцкая (отв. ред.), Ономастика и грамматика. Москва: Наука, lk 98-122.

V a h t e r, Tarmo 2012. Eesti riiki juhivad Miki, Päikesekuningas ja Kosmosemutt. Poliitikute hüüdnimed. - Eesti Ekspress 29. III.

V a i n k ü l a, Kirsti 2015. Kapital nimega Savisaar. - Eesti Ekspress 4. II.

V e r t 2003 = Николай Верт, Россия в революции. Москва: АСТ, Астрель.

V o l g i n, N a r i n s k i 1993 = И. А. Волгин, М. М. Наринский, „Развенчанная тень”. Диалог о Достоевском, Наполеоне и наполеоновском мифе. - А. О. Чубарьян (отв. ред.), Метаморфозы Европы. Москва: Наука, lk 127-164.

W i e d e m a n n, Ferdinand Johann 1973. Eesti-saksa sõnaraamat. Estnisch-Deutsches Wörterbuch. Tallinn: Valgus.

Wikileaks: Ilves nimetas Savisaart odavaks populistiks. - Delfi 28. I 2011.

\section{Rhetoric of propagandist labelling}

Keywords: propaganda, labelling, Edgar Savisaar, myth, anecdote

The labelling of the adversary in the propaganda war is a process of two steps. To exchange a personal name for a befitting nickname you have, first, to introduce and inculcate a - mostly implicit, covert - by-name which is apposite thanks to not only external features of the adversary or his actual behaviour $(N N \rightarrow$ caligula; in Estonian the personal character name is spelled with a minuscule). A surficial nickname will not stick in the face of a possible change of appearance or occupation. Secondly, you have to generalize the character name to a type name (caligula $\rightarrow$ Tyrant; majuscule in Estonian). If the second step is taken before the first, the 
nicknames remain simply occasional and increase in number until no one of them is binding any more (the audience loses the orientation) and the most convenient substitute for them in toto becomes the initial personal name - but now used as a label („NN”; in inverted commas). The character name is an imagological construct. Chosen accordingly, it can influence the functioning of "NN" as a label for either an anecdotal or a mythical figure. An anecdote refers to a real event, whereas a myth can be entirely a lie without any possibility of correction. An anecdote revives the past, a myth casts spells about the future. The heart of an anecdote is the point, the (re)generating core of a myth is the symbol. An anecdotal person is odd and makes us laugh, a mythical figure is mysterious and inspires subconscious terror. A person's mythical name serves as a comparison (prince Charles: „Putin's Hitlerist behaviour"), a mythical person is hardly compared to anyone (Hitler like ... who?).

Linnar Priimägi (b. 1954), PhD, Tallinn University, Department of Advertising and Image Studies, Associate Professor, tristan@tlu.ee 